\title{
AVALIAÇÃO DA QUALIDADE AMBIENTAL DA ARBORIZAÇÃO DE RUAS NOS BAIRROS ALDEOTA E MESSEJANA, FORTALEZA/CE
}

\author{
Renata Leite da Silva Freire ${ }^{1}$, Adeildo Cabral da Silva ${ }^{2}$, João Medeiros Tavares Júnior ${ }^{3}$
}

\section{RESUMO}

O processo de urbanização de uma cidade causa desequilíbrio ambiental, tanto no meio biótico como abiótico, ocasionando sérios transtornos à população e a sua qualidade de vida. Este trabalho apresenta uma avaliação da qualidade ambiental da arborização urbana em seis ruas localizadas nos bairros Aldeota e Messejana do município de Fortaleza. A pesquisa foi realizada utilizando análise quantitativa por meio de um inventário da arborização. Foram identificadas variáveis relacionadas à qualidade ambiental da arborização urbana. Os resultados mostraram que a arborização urbana, nas ruas estudadas, apresentou problemas em suas condições físico-sanitárias, ocasionados pela incompatibilidade das espécies vegetais plantadas no espaço disponível, provenientes de uma implantação da arborização sem orientação técnica e sem um manejo adequado, gerando insatisfação e transtornos para a população e tornando a arborização urbana pouco funcional em seus benefícios ambientais.

Palavras-chave: Gestão Pública, inventário da arborização, qualidade de vida.

\section{QUALITY ENVIRONMENTAL EVALUATION OF ARBORIZATION IN DISTRICTS OF ALDEOTA AND MESSEJANA IN FORTALEZA/CE (BRASIL)}

\begin{abstract}
The process of city urbanization usually leads to environmental imbalance, in both abiotic and biotic environment, affecting the population life quality. This paper evaluated the environmental quality of urban trees six street in the districts of Aldeota and Messejana in the city of Fortaleza/CE (Brasil). The survey was developed using quantitative analysis of an arborization inventory. Variables, related to environmental quality of urbanarborization, were identified. The results showed that the urban arborization in the studied districts had problems in their physical-sanitary conditions, caused by the incompatibility of planted species with the available space and by arborization without technical guidance and proper management. Major consequences of this scenario were dissatisfaction and inconvenience to people, making urban arborization barely functional in their environmental benefits.
\end{abstract}

Keywords: Public management, arborization inventory, life quality

\footnotetext{
${ }^{1}$ Engenheira Florestal, mestre em Tecnologia e Gestão Ambiental e Analista Ambiental do IBAMA/CE. renata@polosolucoes.com.br.

${ }^{2}$ Geógrafo, Professor Doutor do Departamento de construção Civil e Programa de Pós-Graduação Tecnologia e Gestão Ambiental do IFCE. cabral@ifce.edu.br.

${ }^{3}$ Engenheiro de Materiais, Professor Doutor do Departamento da Industria do IFCE.

${ }^{4}$ (recebido em 28.07.2011 e aceito para publicação em 15.06.2012)
} 


\section{INTRODUÇÃO}

As áreas urbanas sofrem constantemente alterações no uso do solo, pelas ações predadoras do Homem, que cada vez mais despreza os valores da natureza.

Assim, o ambiente, que antes era ocupado por um ecossistema natural e equilibrado, hoje mostra marcas e efeitos da ação humana que redundam em graves transtornos ambientais, como a poluição do ar, da água e do solo, alterações climáticas e diminuição da biodiversidade. Segundo Cortez (2000), o registro oficial da arborização urbana em Fortaleza se deu na segunda metade do século XIX, com a arborização da praça do Ferreira e praça José de Alencar. Apenas no final dos anos 20, início dos anos 30 começou a arborização de ruas e avenidas.

A vegetação florestal nativa de Fortaleza vem diminuindo ao longo do seu processo de urbanização. Em 1968, a vegetação nativa representava 65,79\% da área; em 1990, 16,64\% e, em 2002, restavam apenas 7,6\% de vegetação florestal nativa (SEMAM, 2003). A vegetação localizada no meio urbano é considerada de alta importância na melhoria da qualidade ambiental e na qualidade de vida nos grandes centros. No entanto, a arborização de cidades vem sendo realizada sem planejamento e sem respeito às técnicas necessárias. Introduzir uma espécie de ecossistema natural para as condições adversas do ambiente urbano é complicado, principalmente sem o conhecimento especializado para o seu manejo adequado, podendo trazer transtornos e reduzir os benefícios que uma árvore pode proporcionar, tendo muitas vezes que sacrificar a espécie e o próprio bem-estar da população (LOBODA et al., 2005). Assim, a relação entre a arborização e os elementos físicos do ambiente urbano vem, em boa parte dos casos, sendo implantada de forma conflituosa, na qual um dos elementos passa a representar obstáculo à presença do outro. Isto porque a arborização é implantada de forma mal planejada, acarretando sérios problemas como interrupções no fornecimento de energia, perda da eficiência da iluminação pública, entupimento de calhas e bueiros, danos aos muros, telhados e calçada, além da dificuldade para passagem de veículos ou pedestres.
Em muitas situações, o planejamento urbano deixa de incluir a arborização como uma atividade a ser devidamente planejada, permitindo, muitas vezes, que iniciativas particulares pontuais e desprovidas de conhecimento técnico atualizado tomem espaço com plantios irregulares de espécies sem a compatibilidade com o planejamento urbano. Essa situação é traduzida em perda da eficácia da arborização para transmitir conforto físico e psíquico (SILVA FILHO et al., 2002).

Apesar das importantes funções ambientais proporcionadas pela arborização urbana, a população das cidades nem sempre está consciente da necessidade de um manejo adequado das árvores e, muitas vezes, não contribui para a sua manutenção. Aliado a isto, a falta de um planejamento adequado não permite aproveitar todas as vantagens e benefícios que a arborização proporciona em uma cidade (TIMO, 2001). Segundo Silva et al, 2008, no planejamento urbano deve ser considerada a paisagem atual, evitando transtorno como a poda drástica ou a retirada de uma árvore por conflitos com a sinalização, pois a arborização não deve dificultar a visibilidade da sinalização, devendo ser evitado à colocação de placas próximas às árvores. Uma vez estabelecido o problema, deve-se proceder a poda de segurança, eliminando dessa maneira, apenas os galhos que estejam encobrindo a sinalização.

Ainda de acordo com os autores a educação ambiental deve ser uma meta prioritária dos órgãos públicos, evitando principalmente as ações de vandalismo na paisagem urbana. A estrutura de uma árvore, com suas raízes, tronco, galhos e folhas, constitui elemento prédefinido de acordo com as características botânicas da espécie a que pertence. Por intermédio do componente genético, portanto, o tipo e o comportamento das várias espécies arbóreas são diferenciados. Logo, o conhecimento dessas características é fundamental para que o plantio de uma árvore atinja os objetivos esperados. Por isso, não se pode esperar, por exemplo, que um flamboyant (Delonix regia), com sua copa ampla, seja uma espécie recomendada para ruas com uma estreita 
calçada, sem que ocorram danos tanto à árvore quanto aos equipamentos públicos.

Nesse contexto, o presente trabalho teve o objetivo de avaliar a qualidade ambiental da arborização urbana em Fortaleza por meio de inventário, o qual se utilizou amostras intencionais em seis ruas dos bairros Messejana e Aldeota, e nestas a aplicação de formulários e questionários de campo que possibilitaram o levantamento de variáveis relacionadas à qualidade ambiental, aplicados nos bairros estudados.

Figura 01. Localização dos Bairros no município de Fortaleza: 1 - Aldeota e 2 - Messejana

Figure 01. Location of districts in the Fortaleza city: 1 - Aldeota and 2 - Messejana

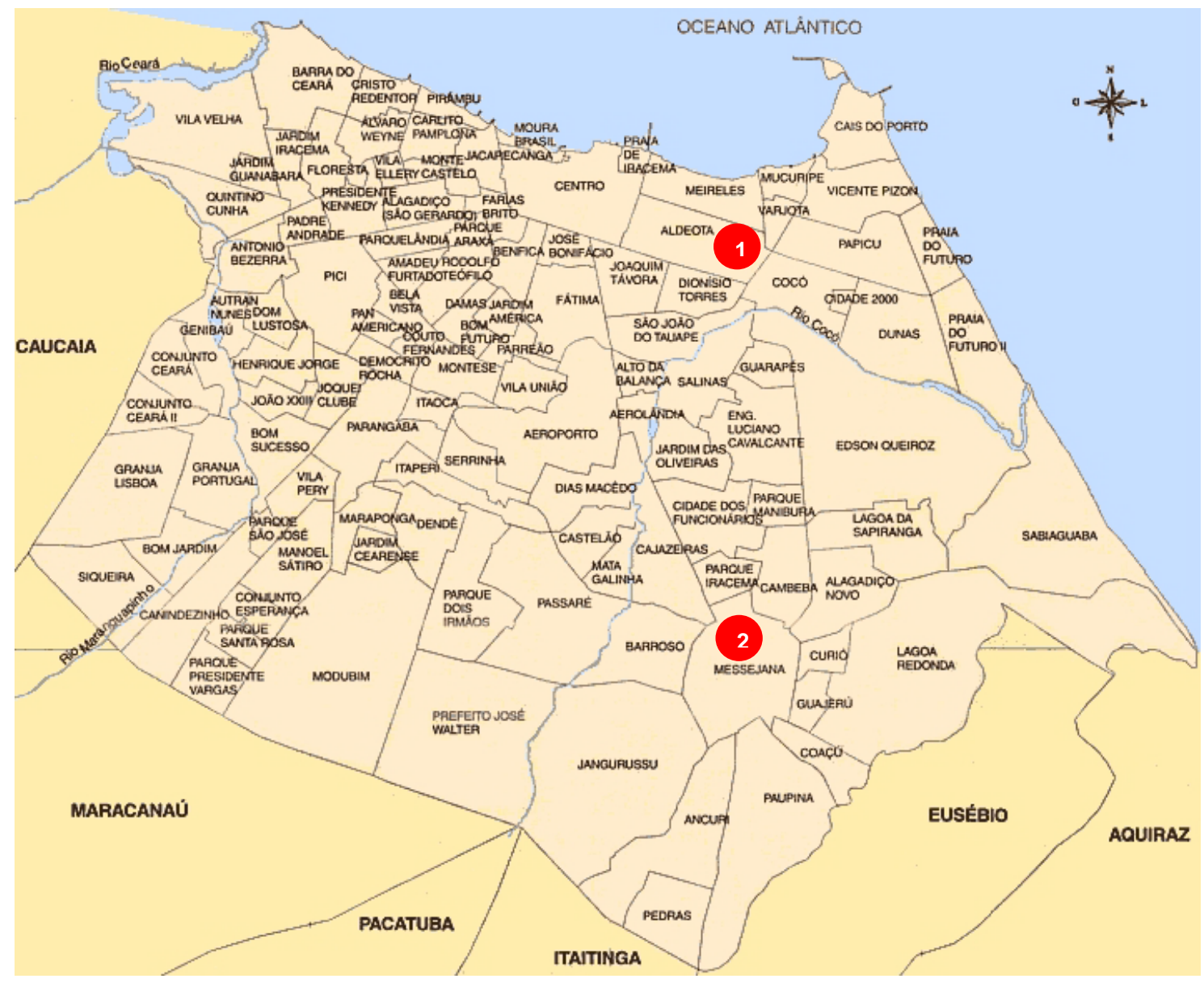

Fonte: www.ceara.com.br/fortaleza/mapadefortaleza.htm, adaptação dos autores, 2012.

\section{MATERIAL E MÉTODOS}

\section{Área de estudo}

O levantamento de campo foi realizado no município de Fortaleza, abrangendo ruas dos bairros Aldeota e Messejana como mostra as figuras 02 e 03. 
Figura 02. Bairro Aldeota, com a localização das ruas estudadas: 1 - Barão de Aracati e 2 - Afonso Celso

Figure 02. Aldeota districts, with the location of streets studied: 1 - Barão de Aracati and 2 - Afonso Celso

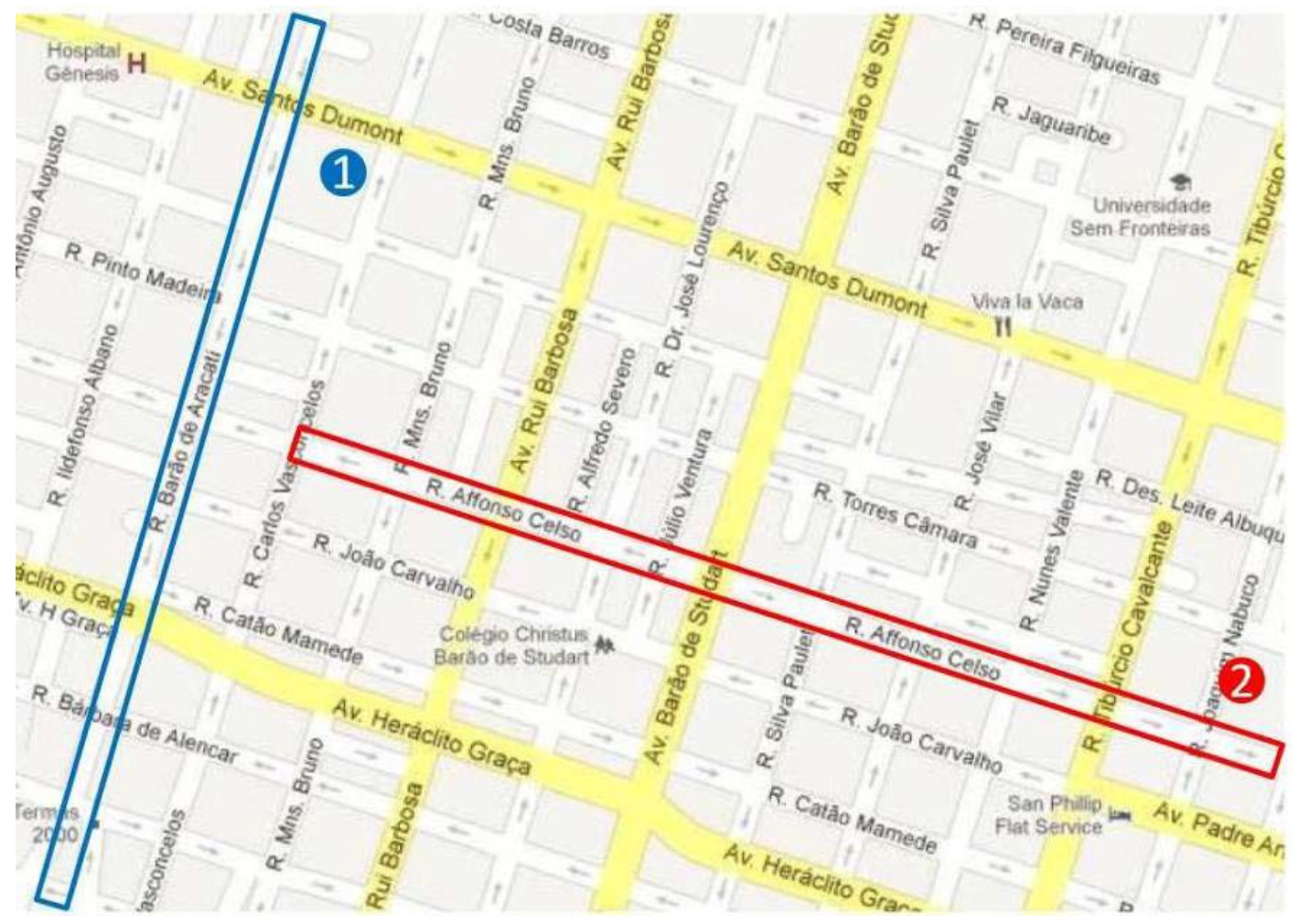

Fonte: http://maps.google.com.br/maps?hl=pt-BR\&tab=wl, adaptação dos autores, 2012.

Figura 03. Bairro de Messejana , com a localização das ruas estudadas: 1 - Capanema; 2 - Pero Vaz; 3 - Maria José Weyne e 4 - Joaquim Felício

Figure 03. Messejana districts, with the location of streets studied: 1 - Capanema; 2 - Pero Vaz; 3 - Maria José Weyne and 4 - Joaquim Felício

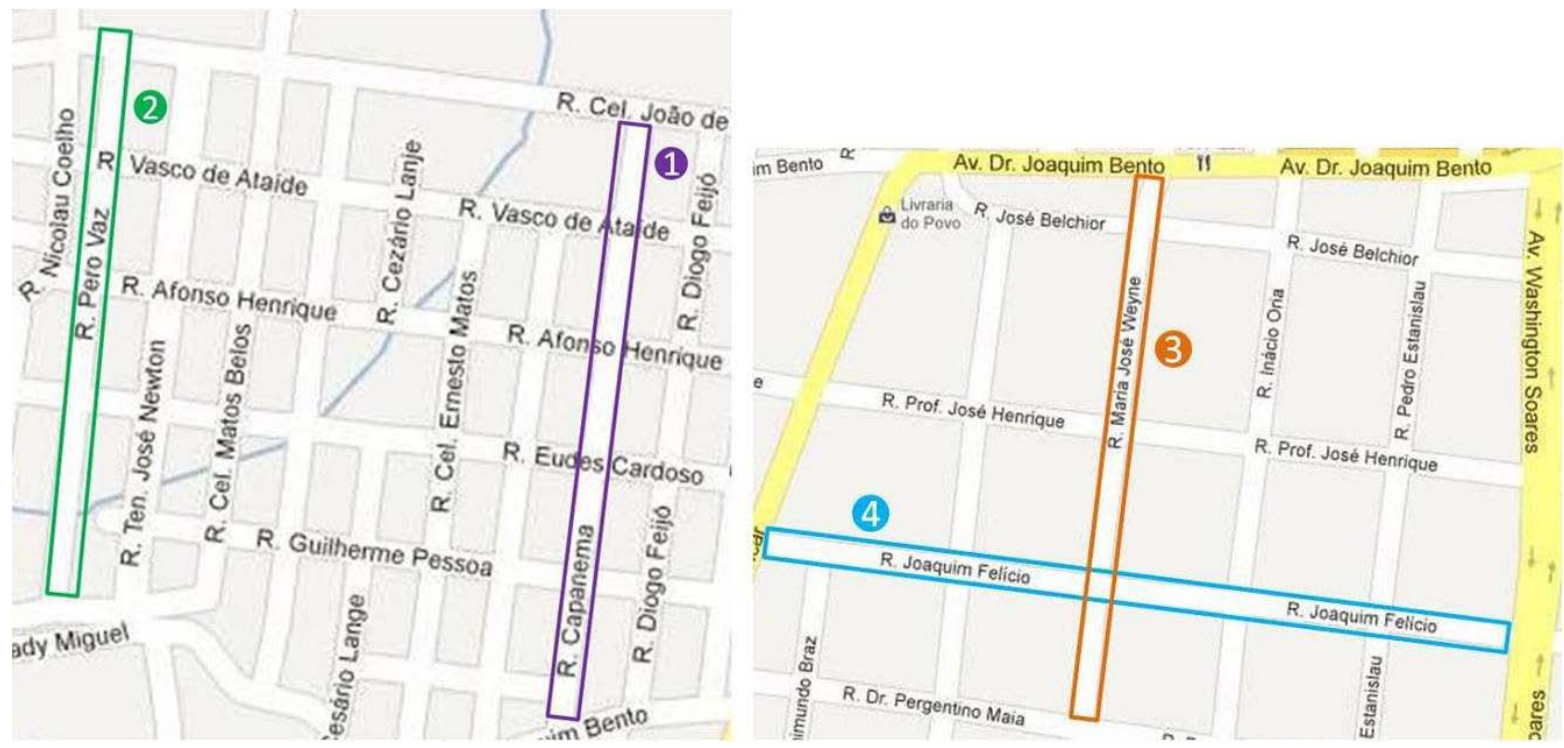

Fonte: http://maps.google.com.br/maps?hl=pt-BR\&tab=wl, adaptação dos autores, 2012. 


\section{Amostragem}

As amostras coletadas foram do tipo intencional, que segundo Gil (1991, p. 32) tem a seguinte definição: "Amostras Intencionais: escolhidos casos para a amostra que representem o "bom julgamento" da população/universo". Considerando uma amostra cada rua levantada por bairro e uma unidade amostral cada árvore identificada na amostra. A escolha dos bairros Aldeota e Messejana foi motivada pelas diferenças sócio econômica, onde Aldeota apresenta um alto poder aquisitivo e Messejana um baixo poder aquisitivo. A referência utilizada para coleta de dados foi o mapa oficial do município de Fortaleza, de ruas e quadras, na escala 1:25.000 do ano de 2007. Por meio dele, foi possível identificar quatros ruas do bairro de Messejana, com 104 unidades amostrais, e duas ruas do bairro Aldeota, com 127 unidades amostrais.

O levantamento de campo foi realizado por meio de inventário da arborização urbana. Durante o levantamento, identificaram-se variáveis relacionadas à qualidade ambiental e efetividade da manutenção da arborização urbana. Para tanto, foram utilizados formulários para a coleta dos indicadores de cada unidade amostral, ou seja, de cada árvore plantada, considerando todas as árvores acima de um metro de altura.

Para cada quadra, o lado sem arborização era apenas contabilizado, e o lado arborizado era mensurado e analisado.

Durante o inventário da arborização foi utilizado o formulário criado pela Professora Isabelle Maria Jacqueline Meunier da Universidade Federal Rural de Pernambuco em 2005 e adaptado para este trabalho. Na ocasião foram preenchidos 231 formulários durante o levantamento, que permitiram a coleta de dados quantitativos, com a finalidade de identificar a qualidade ambiental e a efetividade da manutenção da arborização urbana.

\section{Análises dos dados}

Os dados quantitativos obtidos no inventário da arborização no levantamento de campo foram tabulados em planilhas eletrônicas, elaboradas para esta pesquisa. Após a tabulação de todos os dados, foram analisados estatisticamente, determinando a média, freqüência absoluta, freqüência relativa e valores mínimos e máximos das variáveis.

\section{RESULTADOS E DISCUSSÕES}

No bairro de Messejana foram percorridas quatro ruas e no bairro Aldeota, onde as ruas apresentam maior extensão, foram percorridas apenas duas, sendo suficientes para os manifestos das variáveis em estudo. Nesse percurso, totalizou-se uma análise de 104 árvores e 28 quadras no bairro Messejana e 127 árvores e 36 quadras no bairro Aldeota.

No bairro Messejana, foi encontrado um total de 47 quadras em quatro ruas percorridas, apresentando apenas 28 quadras arborizadas. No bairro Aldeota, com duas ruas percorridas, foram encontradas 44 quadras, com 36 quadras arborizadas.
As espécies vegetais encontradas nos bairros estudados apresentaram uma predominância de espécies exóticas.

O Quadro 01 mostra que a espécie Ficus sp. predomina no bairro Messejana, com 57\% de freqüência, seguida da espécie Syzygium jambos, com 22\% de freqüência. São espécies exóticas e com algumas limitações físicas para sua utilização na arborização urbana, principalmente no que tange à compatibilidade de espaço para o seu desenvolvimento, tanto quanto ao porte delas, quanto ao seu sistema radicular, que, no caso do Ficus sp., apresenta sistema radicular bastante agressivo, não existindo obstáculos para sua busca por água, afetando muitas vezes calçadas e construções. 
No bairro Aldeota, apresentou-se uma diversidade maior de espécies vegetais, porém o Fícus sp. é destacado pelos 35\% de freqüência, seguido da espécie Cassia seamia com 16\% de freqüência. Apesar de exótica, a Cassia seami é uma árvore bastante comum na arborização de ruas, pelo seu crescimento rápido, exuberância na floração e pela sua rusticidade, sendo tolerantes às diversidades edafo-climáticas do ambiente urbano.

Quadro 01. Lista das espécies vegetais encontradas nas ruas dos bairros: Aldeota e Messejana

Picture 01. List of plant species found on the streets of districts: Aldeota and Messejana

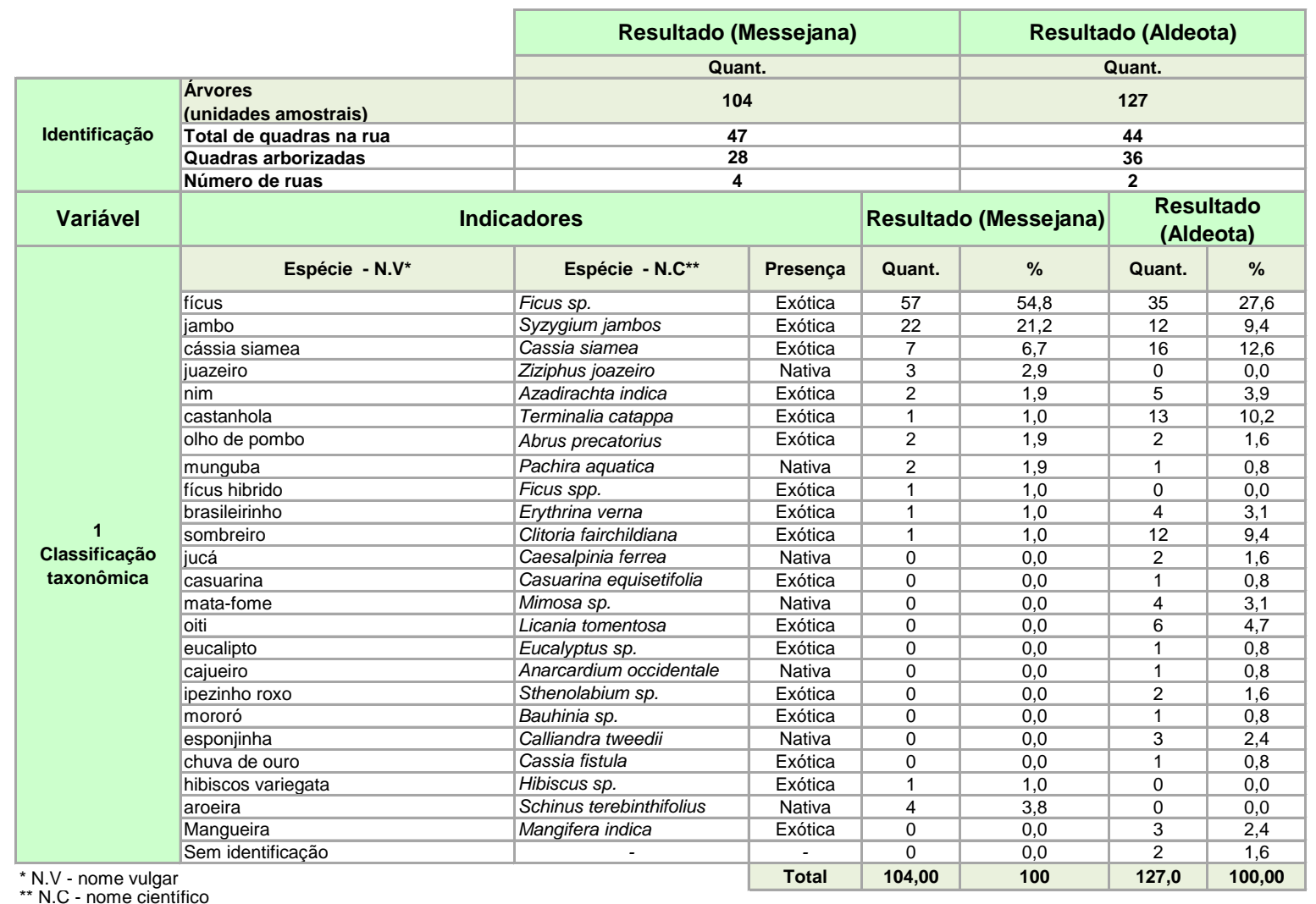

A figura 04 apresenta as principais espécies encontradas na arborização urbana, nas ruas dos bairros Aldeota e Messejana.

Analisando os elementos físicos da arborização, considerou-se também o espaçamento entre as espécies, apenas por quarteirões, e a presença ou ausência da área de crescimento da árvore. O Quadro 02 mostra a qualidade física da arborização nos bairros Aldeota e Messejana. 
Figura 04. 1: Espécie de fícus e 2: Espécie de munguba encontradas nas ruas Pero Vaz e Maria José Weyne, bairro Messejana; 3: Espécie de jambo e 4: Espécie de olho de pombo encontradas na rua Afonso Celso, bairro Aldeota (2007)

Figure 04. 1: Species of ficus and 2: Species of Munguba found on the Pero Vaz e Maria José Weyne streets, Messejana districts, 3: Species of Jambo and 4: Species of olho de pombo found on the Afonso Celso street, Aldeota districts (2007)
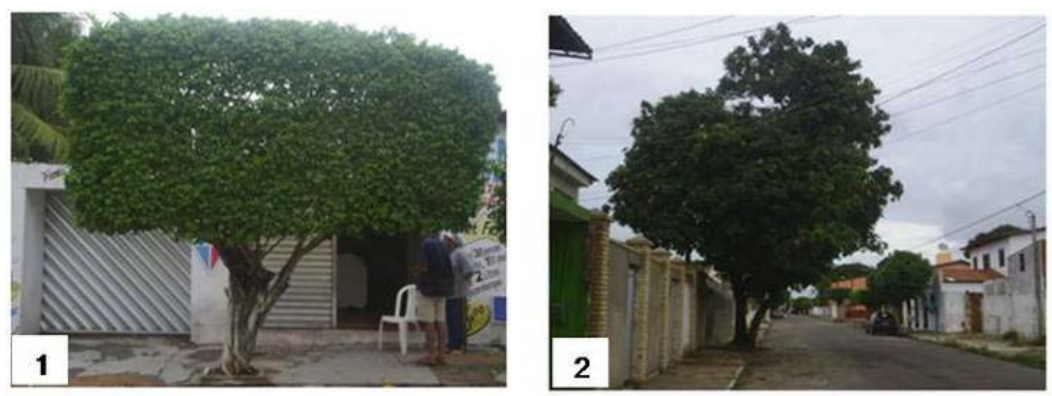

Bairro Messejana

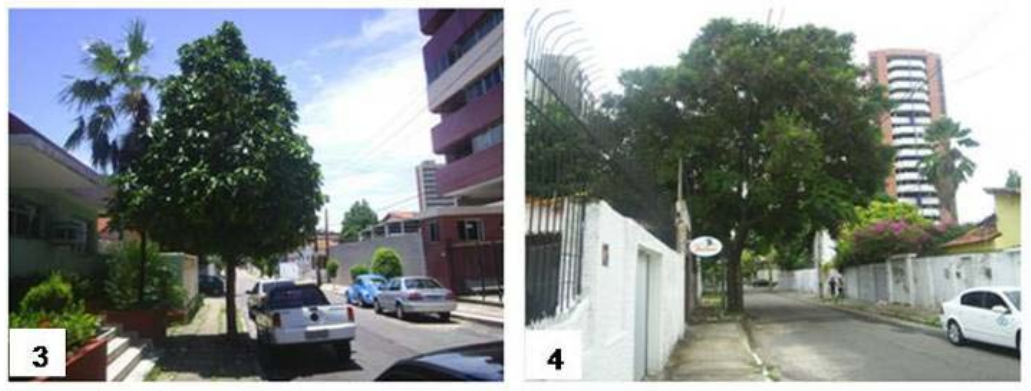

Bairro Aldeota

Tabela 02. Indicadores da qualidade física da arborização urbana

Table 02. Indicators of physical quality of urban arborization

\begin{tabular}{|c|c|c|c|c|c|c|c|}
\hline Variável & Indicadores & \multicolumn{3}{|c|}{ Resultado (Messejana) } & \multicolumn{3}{|c|}{ Resultado (Aldeota) } \\
\hline \multirow{11}{*}{$\stackrel{2}{\text { Qualidade Física }}$} & \multirow{2}{*}{ Largura da rua (m) } & \multirow{2}{*}{\multicolumn{3}{|c|}{ Média }} & \multicolumn{3}{|c|}{ Média } \\
\hline & & & & & \multicolumn{3}{|c|}{7,74} \\
\hline & \multirow{2}{*}{ Distância do meio-fio (m) } & Média & Val.min & Val.máx & Média & Val.min & Val.máx \\
\hline & & 0,30 & 0,00 & 0,90 & 0,45 & 0,00 & 5,40 \\
\hline & \multirow{2}{*}{ Distância do muro ou limite (m) } & Média & Val.min & Val.máx & Média & Val.min & Val.máx \\
\hline & & 1,40 & 0,00 & 13,90 & 1,98 & 0,80 & 9,30 \\
\hline & Área de crescimento & Quant. & \multicolumn{2}{|c|}{$\%$} & Quant. & \multicolumn{2}{|c|}{$\%$} \\
\hline & a - Com área de crescimento & 58 & \multirow{2}{*}{\multicolumn{2}{|c|}{$\begin{array}{l}55,77 \\
44,23\end{array}$}} & 74 & \multicolumn{2}{|c|}{58,27} \\
\hline & b- Sem área de crescimento & 46 & & & 53 & \multicolumn{2}{|c|}{41,73} \\
\hline & \multirow{2}{*}{ Espaçamento entre as árvores (m) } & Média & Val.min & Val.máx & Média & Val.min & Val.máx \\
\hline & & 14 & 2,60 & 59,70 & 12 & 2,50 & 65,70 \\
\hline
\end{tabular}

No bairro Aldeota, foi observada uma distância média do meio-fio de 0,45 metros, um valor máximo de 5,40 metros e um valor mínimo de zero metro e, no que diz respeito ao muro limite médio, uma distância de 1,98 metros, um valor máximo de 9,30 metros e mínimo de 0,80 metros. Em casos em que o terreno apresentava um recuo maior, as árvores em sua maioria foram plantadas no meio da calçada, justificando a presença de valores altos da distância do meio-fio e da distância do muro limite; já em casos de espécies mais antigas com diâmetro elevado e com raízes deslocando a pedra do meio-fio, apresentou-se uma distância nula do meio-fio.

No bairro Messejana, apresentou-se uma distância média do meio-fio de 0,30 metros, um valor máximo de 0,90 
metros e um valor mínimo de zero metro e, em relação ao muro limite médio, uma distância de 1,40 metros, um valor máximo de 13,90 metros e mínimo de zero metro. Em caso específico, ressalta-se que a largura da calçada em Messejana é menor que na Aldeota, tendo restrições para o plantio de espécies arbóreas de porte elevado nas calçadas, causando o deslocamento da pedra do meio-fio e, em algumas ocasiões, a interferência na construção do imóvel, justificando a distância nula do meio-fio e da distância até o muro limite. Na Figura 04, mostra-se a ocupação das espécies de jambo em grande parte da calçada em uma rua do bairro Messejana, dificultando a passagem de pedestre.

Figura 05. Espécies de jambo no bairro de Messejana ocupando a calçada (2007)

Figure 05. Species of Jambo in the Messejana districts occupying sidewalk (2007)

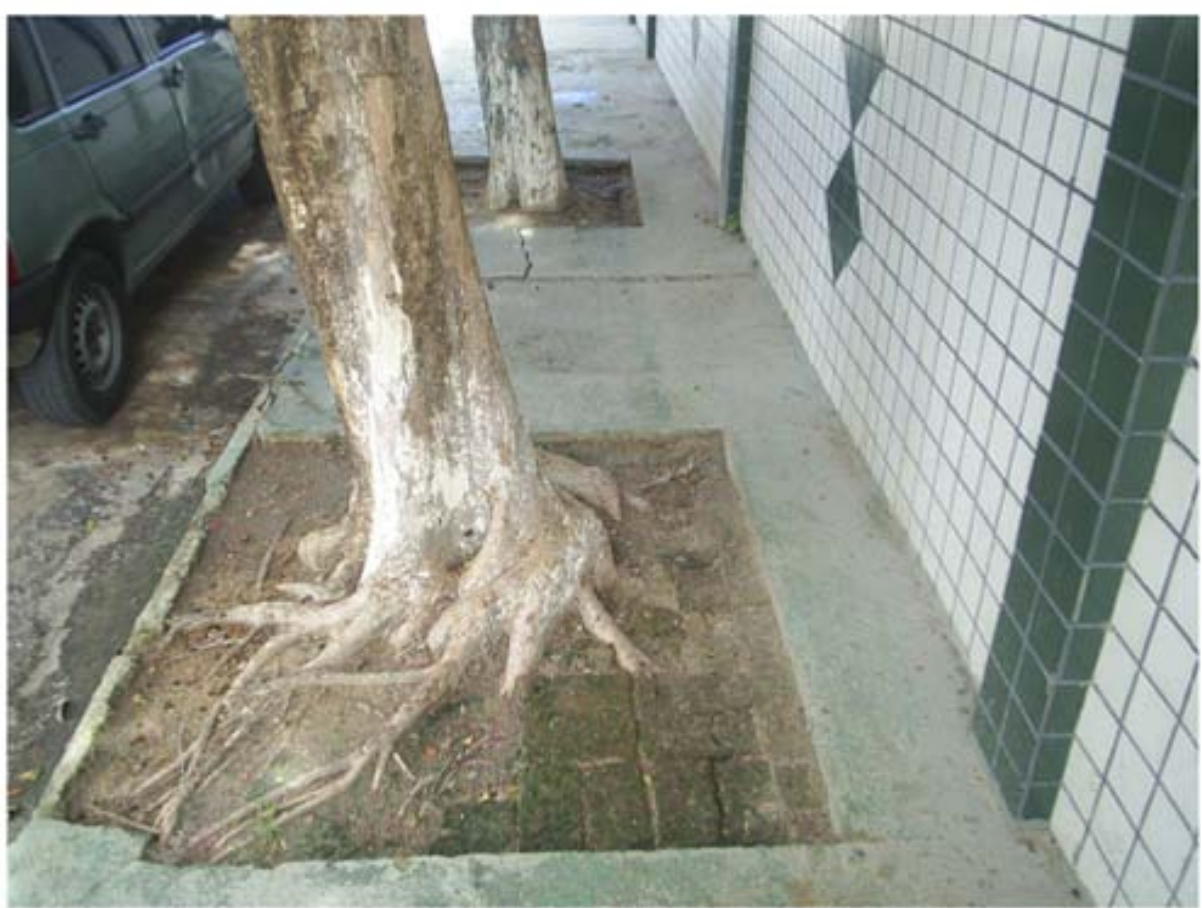

De maneira geral, entre as árvores que apresentaram áreas de crescimento, observou-se um espaço pequeno para permitir a respiração do solo e, nos casos de ausência da área de crescimento, constatou-se a impermeabilização total até o colo das árvores, dificultando a respiração do solo e a infiltração da água da chuva.

O sistema radicular das árvores estudadas foi analisado considerando-se a presença ou não do afloramento das raízes e os tipos de afloramentos presentes. O afloramento das raízes pode indicar escolha inadequada das espécies para o ambiente nas seguintes situações; a ausência ou pequena área de crescimento não permitindo a respiração das raízes e a baixa infiltração da água da chuva tornando as raízes agressivas na busca desse recurso.

As Condições físico-sanitárias são variáveis que tratam das condições em que se encontram as árvores. De forma geral são expressas pela vitalidade, pela situação sanitária das árvores, pela recuperação das árvores após a poda e pelos tipos de doenças e/ou pragas presentes.

O Quadro 03 mostra as condições físico-sanitárias das árvores nos bairros Aldeota e Messejana. 
Tabela 03. Condições físico-sanitárias das árvores da arborização dos bairros Aldeota e de Messejana

Table 03. Physical-sanitary conditions of arborization trees in the Aldeota and Messejana districts

\begin{tabular}{|c|c|c|c|c|c|}
\hline Variável & Vitalidade & \multicolumn{2}{|c|}{ Resultado (Messejana) } & \multicolumn{2}{|c|}{ Resultado (Aldeota) } \\
\hline \multirow{15}{*}{$\begin{array}{c}3 \\
\text { Condições } \\
\text { físico-sanitárias }\end{array}$} & a - com vitalidade & 89 & 85,6 & 123 & 96,9 \\
\hline & b- sem vitalidade & 15 & 14,4 & 4 & 3,1 \\
\hline & a - sem podas anteriores & 12 & 11,5 & 28 & 22,0 \\
\hline & b- com boa recuperação & 57 & 54,8 & 40 & 31,5 \\
\hline & c - com má recuperação & 35 & 33,7 & 59 & 46,5 \\
\hline & c- sem interferência & 2 & 1,9 & 16 & 12,6 \\
\hline & Interferência da copa & Quant. & $\%$ & Quant. & $\%$ \\
\hline & a - sem interferência & 37 & 35,6 & 36 & 28,3 \\
\hline & b- no transito de pedestre & 19 & 18,3 & 9 & 7,1 \\
\hline & c - no trânsito de veículos & 4 & 3,8 & 26 & 20,5 \\
\hline & d - na fiação & 42 & 40,4 & 75 & 59,1 \\
\hline & Tipos de doenças/Pragas & Quant. & $\%$ & Quant. & $\%$ \\
\hline & ataque de insetos & 82 & 91,1 & 111 & 90,2 \\
\hline & parasitas & 0 & 0,0 & 8 & 6,5 \\
\hline & infecção & 8 & 8,9 & 4 & 3,3 \\
\hline
\end{tabular}

Foram observadas a presença ou ausência de podas anteriores nas árvores, bem como a recuperação dos ramos que sofreram a poda. As que apresentaram uma cicatrização boa nos ramos que foram cortados caracterizaram-se como árvores de boa recuperação, e as árvores podadas sem sinais de cicatrização e que apresentaram algum tipo de inseto saprófago foram consideradas como árvores de má recuperação. Esse indicador leva a uma potencial situação problema; proliferação de doenças e pragas, já que a árvore sofreu injúria e não se recuperou. A Figura 06 mostra o percentual de árvores que apresentaram podas anteriores e sua recuperação.

Figura 06. Podas anteriores existentes em Messejana e na Aldeota

Figure 06. Pruning previous and existing Messejana and Aldeota
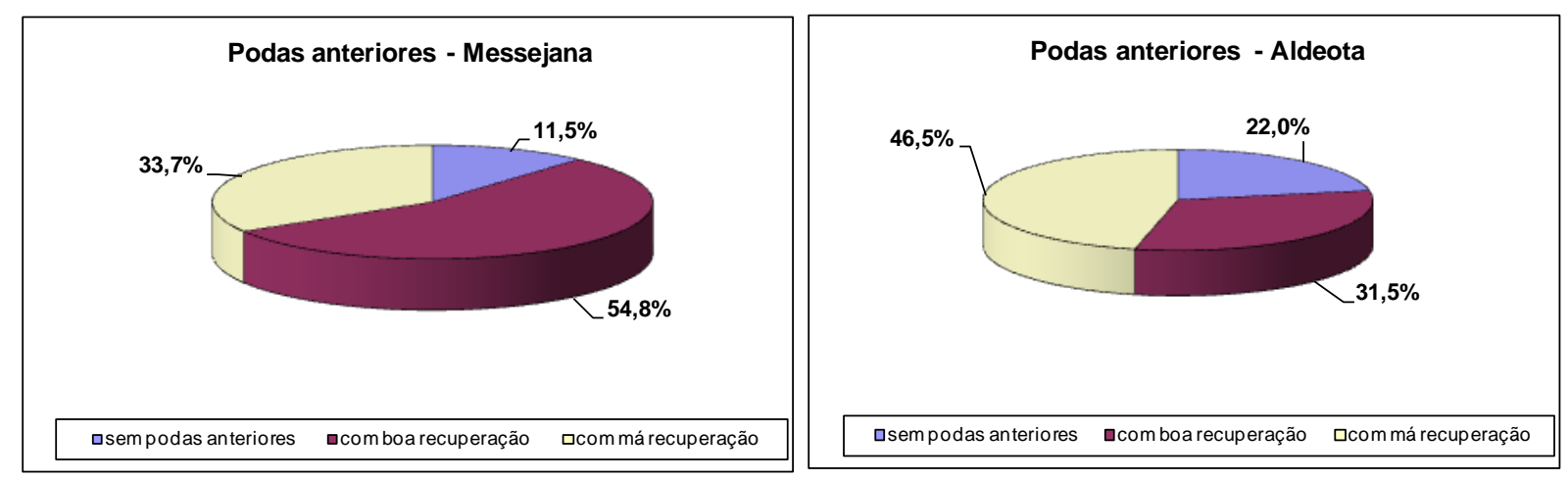
O bairro Messejana apresentou 54\% das árvores com boa recuperação das podas, já, no bairro Aldeota, apenas $31 \%$. Quanto às árvores com má recuperação das podas, o bairro Aldeota apresentou 47\% contra 34\% do bairro Messejana.

O fato de o bairro Messejana ter apresentado uma melhor recuperação das podas pode ser explicado pela realização das podas em grande maioria nas espécies de Ficus sp., espécie resistente às podas e topearias, além de serem realizadas pelos próprios moradores. No caso do bairro Aldeota, as podas são realizadas, na maioria das vezes, pela Companhia Elétrica do Ceará (COELCE), com o objetivo restrito de retirar os ramos que interferem na fiação elétrica, sem orientação técnica e sem qualquer cuidado para que as árvores sejam mantidas saudáveis.
Considerou-se interferência da copa das árvores, quando os ramos interferem no ambiente físico em que a árvore foi plantada. Foram observados alguns tipos de interferência: a interferência no trânsito de pedestre, quando os ramos e galhos estão baixos ocupando o lado da calçada e dificultando a passagem dos transeuntes; a interferência do veículo, quando os galhos e ramos ocupam o espaço da rua interferindo no trânsito de veículos; a interferência na fiação aérea, quando os ramos ou galhos ultrapassam a altura da fiação, comprometendo a fiação e a interferência na construção, quando os ramos e galhos ultrapassam o muro limite e chegam a interferir na construção do imóvel vizinho.

Figura 07. Tipos de interferência da copa das árvores nas ruas dos bairros Aldeota e Messejana

Figure 07. Types of interference from the treetops in the streets of districts Aldeota and Messejana

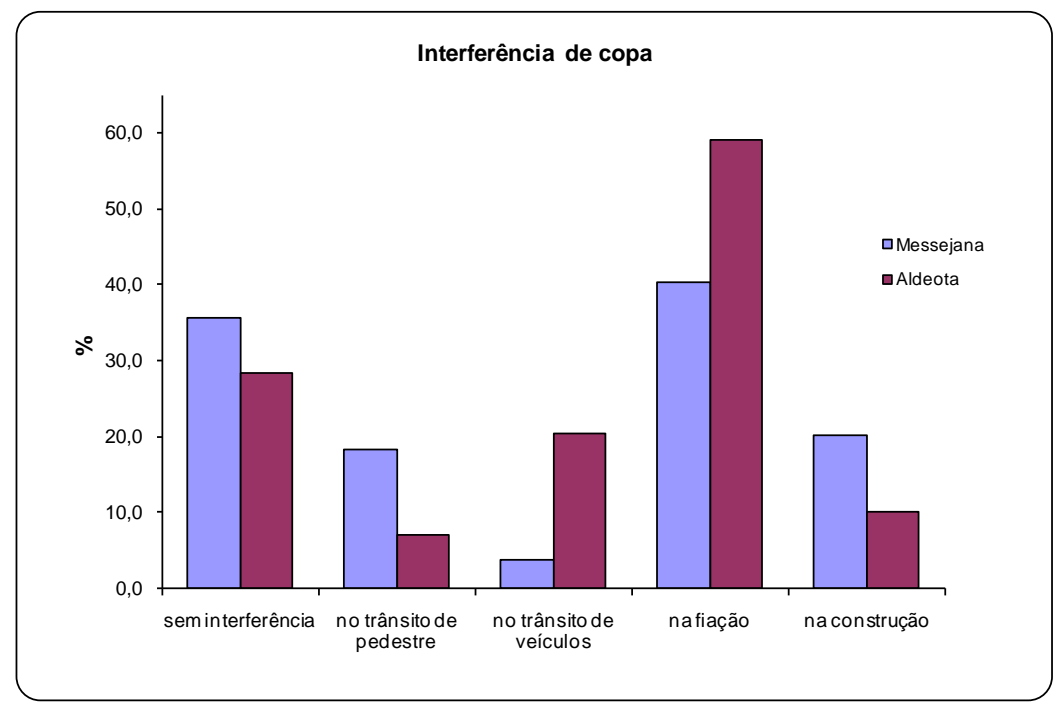

A Figura 07 mostra que o bairro Messejana apresentou 40,40\% das árvores com interferência na fiação aérea, seguidos de 20,20\% com interferência na construção, 18,30\% com interferência no trânsito de pedestres e apenas 4\% com interferência no trânsito de veículos. No bairro Aldeota, 59,10\% das árvores apresentam interferência na fiação elétrica, 28,30\%, interferência no trânsito de veículos, 10,20\%, interferência na construção e 7,10\%, interferência no trânsito de pedestres. A interferência da arborização na fiação aérea é bem significativa em ambos os bairros estudados, mostrando a incompatibilidade das árvores no espaço físico em que são plantadas. No entanto chama-se atenção para um problema significativo no bairro Aldeota, o fato da Companhia Elétrica do Ceará - COELCE estar presente nas manutenções com as atividades de podas emergenciais ou de manutenção para livrar da rede elétrica, sem nenhum critério técnico e nem a preocupação com a recuperação da árvore, mas sim apenas com o objetivo de livrar a fiação elétrica de 
interferências, ocasionando na maioria das vezes uma má recuperação da espécie após as podas e um desequilíbrio das copas.

O bairro Messejana mostra ainda que a interferência na construção e no trânsito de pedestre é bem significativa, o que pode ser explicado pela largura da calçada. No bairro Aldeota, a interferência no tráfego de veículos apresentase bem significativa, principalmente se comparada com o bairro de Messejana, o que pode ser explicado pela largura das ruas, que são mais estreitas no primeiro, ou pela quantidade de espécies presentes, mais antigas e de porte maior, como, por exemplo, as espécies Terminalia cattapa e Licania tomentosa.

Ainda, nas espécies amostradas foram visualizados ataque de insetos, presença de parasitas e infecções diversas. Quanto aos insetos, foi registrada a presença de cupins, formigas, brocas, cochonilhas, lacerdinhas, lagartas entre os mais comuns. Com relação aos parasitas observados, tomou-se o cuidado de se separar os verdadeiros parasitas, que sugam a seiva das plantas até a morte, das plantas epífitas, que precisam da árvore apenas como suporte. Porém, a presença de epífitas nas árvores em grande quantidade pode levar a morte da mesma pela concorrência por luminosidade. A presença de pragas e parasitas presentes na árvore foi considerada independentemente da sua intensidade.

Considerou-se árvore com infecção todas aquelas que apresentaram problemas fisiológicos. O princípio básico para diagnosticar uma árvore doente é o conceito de normalidade da árvore, já que a doença é uma anormalidade. Foram constatadas algumas anormalidades como folhas amareladas, folhas queimadas ou com alguma má formação em suas partes.

Nos bairros estudados, verificou-se mais de $80 \%$ das árvores com presença de doenças ou pragas, número bem significativo e preocupante, demonstrando uma baixa qualidade da arborização.

No bairro Messejana, 91,10\% das doenças e pragas encontradas na arborização foram do tipo ataque de insetos, e 8,90\% apresentaram infecção. No bairro Aldeota, 90,20\% apresentaram ataque de insetos, seguidos de 6,50\% com parasitas e 3,30\% com infecções. Os parasitas encontrados foram $100 \%$ erva de passarinho, e os insetos encontrados foram lacerdinha, cochonilha, cupim e brocas. No caso dos insetos saprófagos, a broca e os cupins foram encontrados, principalmente, em árvores que sofreram podas e apresentaram má recuperação, e a lacerdinha e cochonilha foram predominantes, principalmente, na espécie de Fícus sp., notadamente nas ruas que apresentaram uma predominância do plantio da espécie.

A Figura 08 mostra os tipos de doença e/ou pragas encontradas nos bairros estudados.

Figura 08. Tipos de doenças e pragas nas ruas dos bairros Aldeota e Messejana

Figure 08. Types of diseases and pests in the streets of districts Aldeota and Messejana

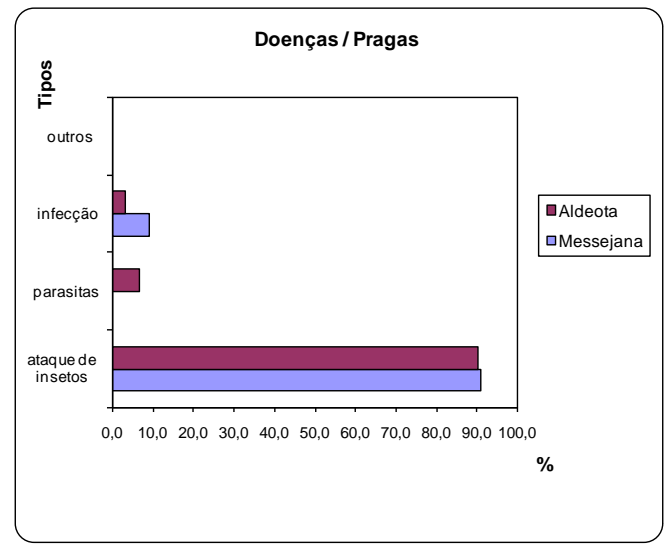




\section{CONCLUSÃO}

A arborização das ruas estudadas dos bairros Aldeota e Messejana apresentaram problemas de incompatibilidade entre o espaço disponível e as espécies plantadas, comprometendo a qualidade ambiental, em seus aspectos físicos da arborização, como mostram os resultados da distância das árvores e o muro limite e o meio-fio, chegando a um valor nulo, ou zero, dificultando o acesso dos transeuntes nas calçadas e o desenvolvimento saudável das espécies. Devido à incompatibilidade do espaço físico para o desenvolvimento das árvores, a arborização nas ruas da Aldeota e de Messejana apresentou mais de $60 \%$ das espécies com afloramento de raízes, principalmente em calçadas, e com mais de $40 \%$ das copas das árvores interferindo na fiação aérea, comprometendo a qualidade física.

Em conseqüência dos problemas físicos, a arborização apresentou problemas fitossanitários, com mais de $80 \%$ das árvores infectadas ou doentes e com mais de 90\% das doenças provenientes de ataques de insetos, principalmente os saprófagos, do tipo broca e cupim, que se alimentam de galhos ou ramos mortos das árvores, causados principalmente por podas irregulares e que apresentam má formação, propiciando a proliferação das doenças e pragas e comprometendo a qualidade ambiental da arborização.

\section{AGRADECIMENTOS}

Á Prof ${ }^{a}$ Dra. Nájila Rejanne Alencar Julião Cabral (IFCE) pelas contribuições dadas. Ao Prof. Dr. Marcondes Araújo Lima, do Departamento de Arquitetura da UFC, pela idéia inicial do projeto e contribuições fornecidas. Ao Prof. Dr. Eduardo Bosco
Cattony (IFCE) pela contribuição na análise final do texto. À Prof ${ }^{\mathrm{a}}$ MS Isabelle Meunier da Universidade Federal Rural de Pernambuco, pela prontidão e essencial ajuda no planejamento para a realização do Inventário da arborização.

\section{REFERÊNCIAS BIBLIOGRÁFICAS}

CORTEZ, A. P. Estado e a Formação da Paisagem Urbana de Fortaleza quanto à Vegetação Arbórea - Enfoques Urbanísticos e de Sustentabilidade. UFC, Fortaleza, 2000. p. 637 - 680. (Dissertação de Mestrado).

GIL, A. C. Como elaborar projetos de pesquisa. Atlas, São Paulo, 1991. p. 45.

LOBODA, C. R., et. al. Avaliação das Áreas Verdes em Espaços Públicos no Município de Guarapuava/PR. In: Scripta Nova - Revista Eletrônica de Geografia y Ciencias Sociales, Vol. IX, num. 194, Universidade de Barcelona, Barcelona, 2005.

MEUNIER, I. Amostragem da Arborização Urbana: Parâmetros Fitossociológicos Adaptados à Análise da Arborização urbana e índice de Diversidade, UFRPE, Recife, 2005. (apostila).

SECRETÁRIA DO MEIO AMBIENTE - SEMAM, Inventário Ambiental de Fortaleza: Diagnóstico, versão final, Fortaleza: ASTEF, 2003.

SILVA FILHO, F., PIZZETTA, P. U. C., ALMEIDA, J. B. S. A., PIVETTA, K. F. L., FERRAUDO, A. S. Banco de Dados Relacional para Cadastro, Avaliação e Manejo da Arborização em Vias Públicas. Revista Árvore, v. 26, n. 5, p. 629-642, 2002.

SILVA, L. M., at al. Inventário da Arborização em Duas Vias de Mariópolis/PR. In: Revista Brasileira de Arborização Urbana - revista on line. Volume 3, Número 1. 2008.

VOLPE-FILIK, A., et al. Avaliação da Arborização de Ruas do Bairro São Dimas Na Cidade de Piracicaba/SP Através de Parâmetros Qualitativos. In: Revista Brasileira de Arborização Urbana - revista on line. Volume 2, Número 1. 2007. 